\title{
VATS Sympathectomy for the management of Primary Hyperhidrosis: An experience at Aseer Central Hospital, Saudi Arabia.
}

1. MRCS, FCPS, FEBTS

Consultant Thoracic Surgeon,

Aseer Central Hospital, Abha Saudi Arabia.

2. FCPS General Surgery

Consultant General Surgeon, Prince Mansour Military Hospital, Taif Saudi Arabia.

3. FCPS (Haematology)

Post Graduate Trainee

Combined Military Hospital (CMH) Multan, Pakistan.

Correspondence Address:

Dr. Javed Mirdad Tarar

Consultant Thoracic Surgeon,

Aseer Central Hospital, Abha Saudi

Arabia.

drjavedtarar@yahoo.com

Article received on:

27/07/2020

Accepted for publication:

$03 / 10 / 2020$

\begin{abstract}
Javed Mirdad Tarar ${ }^{1}$, Kashif Nadeem², Durre Sadaf Khan ${ }^{3}$
ABSTRACT... Background: Hyperhidrosis is bilateral, symmetrical and profuse sweating beyond physiological limits of the body. It is an important disease that causes social and emotional disturbances. Conservative treatment has poor results and most of the patients end up in surgical remedy eventually. The choice of operation is Bilateral Sympathectomy which has excellent results. Objective: The aim of this study was to assess the demographic features of patients and to evaluate the outcome of VATS Sympathectomy. Study Design: Prospective Study. Setting: Aseer Central Hospital, Saudi Arabia. Period: September 2017 to March 2020. Material \& Methods: Bilateral VATS with resection of sympathetic chain from T2 to T5 was done depending upon the area involved in hyperhidrosis. Results: 28 (58.3\%) male and 20(41.6\%) female patients with mean age 21 years (range 19 to 53 ) were documented. $40 \%$ of the patients related their condition to be familial. Most common site of involvement was combined Palmer Plant and Axillary in 26(54\%) whereas isolated facial hyperhidrosis was the least involved area. Complication rate was $12 \%$ with no mortality recorded. Excellent results with $98 \%$ patient's satisfaction was found. Conclusion: Bilateral VATS sympathectomy is the gold standard surgical treatment for Primary Hyperhidrosis with excellent results.
\end{abstract}

Key words: $\quad$ CS (Compensatory Sweating), Hyperhidrosis, Sympathectomy, VATS (Video Assisted Thoracic Surgery)

Article Citation: Tarar JM, Nadeem K, Khan DS. VATS Sympathectomy for the management of Primary Hyperhidrosis: An experience at Aseer Central Hospital, Saudi Arabia. Professional Med J 2021; 28(8):1126-1131.

https://doi.org/10.29309/TPMJ/2021.28.08.5820

\section{INTRODUCTION}

Hyperhidrosis is defined as excessive and profuse sweating which is bilateral, symmetrical and is beyond the physiological demands of human body. It is classified as primary and secondary. In the absence of any identifiable cause, Primary hyperhidrosis, affects almost $3 \%$ of the western population. ${ }^{1,2}$ Secondary Hyperhidrosis occurs due to some underlying metabolic abnormality like hyperthyroidism, diabetes mellitus or due to hormonal imbalance including pheochromocytoma, Cushing's disease pituitary and carcinoid tumours. It may be associated with other diseases like TB, Lymphoma and Sympathetic nervous disorders. ${ }^{3}$ Primary Hyperhidrosis is an important disease that has severe emotional, social and educational adverse impact on patients. ${ }^{4,5}$ Although Primary Hyperhidrosis is defined as idiopathic, yet it has been suggested to be the result of sympathetic nervous system overactivity. ${ }^{6}$ The diagnosis of primary hyperhidrosis is mainly clinical including detailed medical history and findings of excessive sweating. At present there are no clear objective parameters to label palmer hyperhidrosis but few have suggested that axillary hyperhidrosis may be defines as focal sweat production over 50-100 $\mathrm{mg} / 5$ mins. $^{7}$

\section{Diagnostic Criteria for Primary Hyperhidrosis}

A. Bilateral, Symmetrical excessive sweating for a period of over 6 months

And either 2 of the following:

B. Family history

- Age of onset before 25 years

- Interferes with daily activities

- Occurs at least once a week

- Absence of sweating during sleep 
Though poorly understood, yet it has been found to run in families. At least 30 to $60 \%$ of the patients report it to be familial. Proposed mechanism is autosomal dominant mode of transmission. ${ }^{8,9}$ The sweating in primary hyperhidrosis is aggravated by emotional stress, fear, anger and hot climate. Patients often find themselves socially isolated and are reluctant to participate in sports, educational activities and get together. Many patients seek medical treatment before showing up to Thoracic Surgical services. These non-surgical treatment modalities include, local tinctures and ointments, oral anticholinergics, botulinum toxin injection and lontophoresis. . $^{10,11,12}$ Unfortunately none of these have proven to be long lasting and the only treatment option that has excellent results is surgery. ${ }^{13,14}$ Surgical treatment includes bilateral sympathectomy that historically has been revolutionized by VATS and is the most promising treatment modality.

\section{MATERIAL \& METHODS}

Prospective analysis of 48 patients who underwent bilateral sympathectomies was done between September 2017 to March 2020. Venue of this study was at Aseer Central Hospital, Saudi Arabia. Surgeries were performed by same surgical team under uniform surgical environment. The approval of study from institutional ethical committee was obtained.

All patients of primary hyperhidrosis were included in this study who did not have any prior history of Thoracic Surgical intervention. Also patients with limited cardiorespiratory reserves who could not tolerate single lung ventilation were excluded from the study. Patients with secondary hyperhidrosis were also excluded from the study.

\section{Surgical Technique}

General anesthesia with isolated lung ventilation by means of double lumen endotracheal tube was used. Lateral decubitus position was made and standard triportal VATS was performed without $\mathrm{CO}_{2}$ insufflation. Sympathetic chain was identified at the apex of pleural cavity and special attention was given to count the ribs from above downwards. Harmonic scalpel was used to dissect and transect the sympathetic chain from
$\mathrm{T}_{2}$ downwards until $\mathrm{T}_{5}$ depending on the area of hyperhidrosis involvement. Extra attention was paid to make sure that no remnant of sympathetic chain was left and nerve of Kuntz, if present, were ablated properly. Haemostasis was secured and anesthetist was asked to inflate the lung under vision. Simultaneous Valsalva maneuver by anesthetist and negative suction to pleural cavity resulted in full expansion of lung and port sites were sealed without chest drain placement. Similar procedure with same precautionary measures and technique was performed on the other side as well. All the patients were extubated in operation theatre and were shifted to general surgical floor post operatively without the need of ICU. Post op CXR was performed for each patient and only small rim of pneumothorax $<20 \%$ was observed in $3 \%$ of patients.

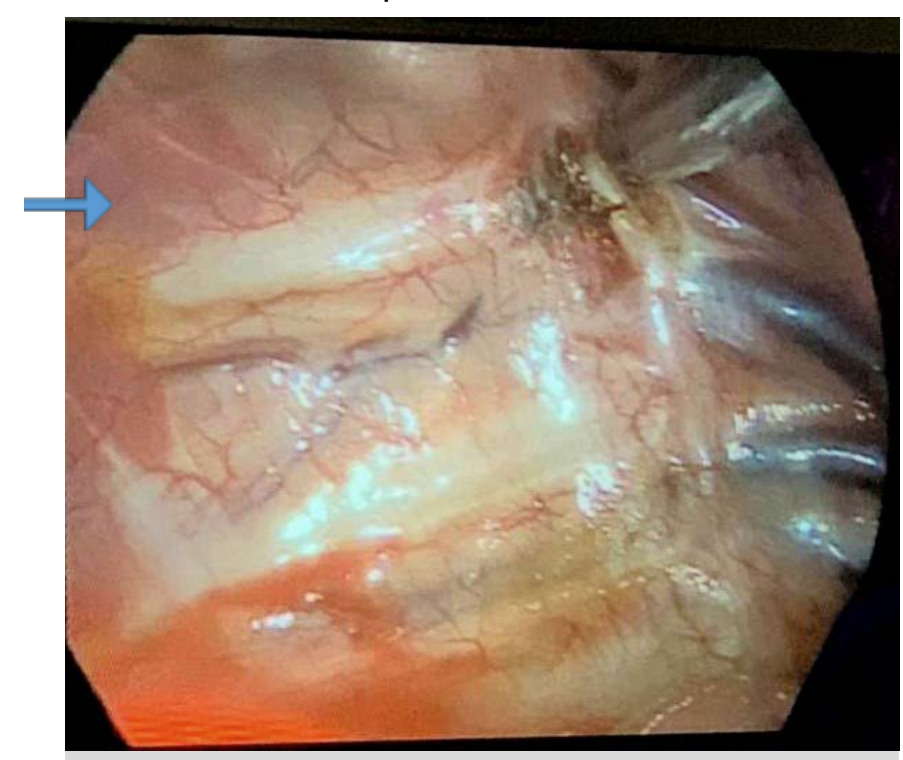

Figure-1: Before Surgery.

Arrow: Sympathetic Chain

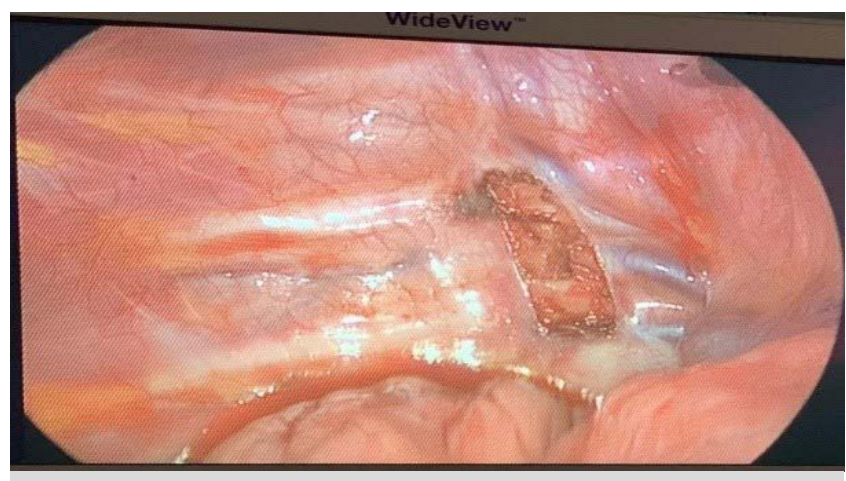

Figure-2: After Surgery. 


\section{Data Analysis}

All the data was statistically analyzed as mean \pm standard deviation and percentages. $T$ test and chi square tests were utilized and $P$ values $<0.05$ were considered statistically significant on SPSS version 20.0.

\section{RESULTS}

Demographics and data of 48 patients with 96 bilateral VATS sympathectomies was collected. 28 patients (58.3\%) were male and 20(41.6\%) were female with mean age 28 years (range 19 to 53). Most prevalent site of involvement was palmar+plant+axillary in 26 patients (54\%) followed by palmar+planter sites in 13 patients (28\%). Isolated facial hyperhidrosis was the least affected area in just 2(4\%) of patients. $78 \%(n=38)$ of patients reported their symptoms to start since early childhood. 21 patients(43.75\%) gave history of some sort of non-surgical treatment before getting surgical management and out of these $18(85.7 \%)$ of patients used anticholinergics and topical ointments/tinctures. All the Patients who underwent surgery showed improvement in their symptoms. Complete resolution was defined as either total alleviation of symptoms or $\geq 2$ points improvement in their HDSS score. Such complete response was observed in 46 patients(96\%) whereas 2 patients(4\%) had partial resolution with decrease in the intensity of sweating and less than 2 points improvement in their HDSS score. $98 \%(n=47)$ of patients were satisfied with the results of surgery and achieved excellent quality of life. Mean hospital stay was $2.36 \pm 0.53$ days. Follow up was maintained for 6 months in OPD. Complications were encountered in 8 (16.6\%) patients. These included compensatory sweating and neuralgic pain in 3(6.25\%) patients each and significant pneumothorax warranting chest tube insertion in $2(4.16 \%)$ patients. No mortality was reported perioperatively in our study.

\section{DISCUSSION}

Hyperhidrosis is characterized by excessive sweating that is beyond physiological limits and requirements. These patients suffer from psychosocial problems and have lack of selfconfidence. ${ }^{15,16,17,18}$ Although primaryhyperhidrosis doesn't have any established underlying cause, yet it is proposed due to sympathetic over activity and autonomic imbalance. ${ }^{19}$

More than half of the patients in our study were males which is in contrast to other studies which show female predominance. ${ }^{20,21,22}$ The justification of this gender based deviation is psychosocial factors in this part of world. Obviously the female population in this society is a bit apprehensive and reluctant to report and seek surgical treatment for such disease entity that involves covered and hidden body parts. However the mean age of patients in our study matched the previous studies. ${ }^{21,22}$ Most affected site was combined palmar, plantar and axillary areas, whereas, isolated facial involvement was the least one. This was in accordance with the previous studies. ${ }^{20,21,22}$ Kuhajda et all and others have reported this condition to be familial and this was in agreement to our study as well. $59 \%$ of our patients had this condition in their families that was reported in other studies too. ${ }^{8,21,23}$ Patients score their disease severity by means of:

\section{HDSS scale.}

\begin{tabular}{|c|l|}
\hline Score & \multicolumn{1}{|c|}{ Explanation } \\
\hline 1 & $\begin{array}{l}\text { Sweating is never noticeable and doesn't } \\
\text { interfere with daily activities. Quality of life } \\
\text { is Excellent }\end{array}$ \\
\hline 2 & $\begin{array}{l}\text { Sweating is tolerable but sometimes } \\
\text { interferes with daily activities. Quality of } \\
\text { life is good. }\end{array}$ \\
\hline 3 & $\begin{array}{l}\text { Sweating is hardly tolerable and frequently } \\
\text { interferes with daily activities. Quality of } \\
\text { life is bad. }\end{array}$ \\
\hline 4 & $\begin{array}{l}\text { Sweating is intolerable and always } \\
\text { interferes with daily activities. } \\
\text { Quality of life is poor. }\end{array}$ \\
\hline
\end{tabular}

The conservative medical treatment options available are either topical applications or oral anticholinergics including glycopyrolate and oxybutynin. Other therapies include lontophoresis and injectable botulinum toxin. ${ }^{24,25}$ None of these have proven to be long lasting and promising as most of the patients eventually end up in surgical management which has excellent results. ${ }^{4,5,16,18,26}$ 
The standard surgical approach is bilateral VATS sympathectomy in these patients. First thoracoscopic sympathectomy for hyperhidrosis was performed in 1978. Since then, refinements in the lens scope system and advancements in anesthesia techniques, this procedure has become the gold standard for hyperhidrosis management today. In our study we utilized GA and single lung ventilation by means of double lumen ETT in accordance with previous studies. ${ }^{18,27,28}$ We didn't use $\mathrm{CO}_{2}$ insufflation to achieve lung collapse like most of the previous studies. ${ }^{16,17,29}$ Sympathetic chain between $T_{2}$ - $T_{5}$ was resected depending upon the area of hyperhidrosis involvement as was done in past studies. ${ }^{30}$ Bilateral ETS was performed and all patients were extubated in OR before shifting to ward. We didn't encounter any major bleeding or pneumothorax perioperatively. Our complication rate was $16.6 \%$ that was similarly shown by Oncel et all. ${ }^{6}$ Most common complication in our study was compensatory sweating in $6.25 \%$ of patients. This incidence was less as documented by others. ${ }^{18,28}$ Multiple justifications could be attributed to this phenomenon including small sample size in our study and sparing of $\mathrm{T}_{2}$. Other factors including geographical and climatic conditions, working environment and subjective emotional status, all play important role in the incidence of compensatory sweating. In accordance with earlier studies, we found excellent results with $96-98 \%$ of the patients reporting improvement in quality of life and satisfaction from the results of surgery. ${ }^{31,32}$ Mean hospital stay in our study (2.36 \pm 0.53 days) was a little longer as shown by Kuhajda et all (1.28 \pm 0.68 days), however, this difference was statistically insignificant.

\section{CONCLUSION}

Bilateral VATS sympathectomy is the gold standard management for primary hyperhidrosis as it has excellent results with minimal complications.

\section{Copyright@ 03 Oct, 2020.}

\section{REFERENCES}

1. Milanez de Campos JR, Kauffman P, de Campos Wereba E, Andrade Filho LO, Kusniek S, Wolosker N. Quality of life, before and after thoracic sympathectomy: report on $\mathbf{3 7 8}$ operated patients. Ann Thorac Surg 2003;76:886-91.
2. Wolosker N, Yazbek G, de Campos JR, Munia MA, Kauffman P, Jatene FB, et al. Quality of life before surgery is predictive factor for satisfaction among patients undergoing sympathectomy to treat hyperhidrosis. J Vasc Surg. 2010;51:1190-4.

3. Doolabh N, Horswell S, Wiliams M, Huber L, Prince S, Meyer DM. Thoracoscopic sympathectomy for hyperhidrosis: indications and results. Ann Thorac Surg 2004;77:410-4.

4. DeCampos JR, Kauffman P, WerebeEde C, Andrade Filho LO, Kusniek S, Wolosker N, Jatene FB (2003) Quality of life, before and after thoracic sympathectomy: report on 378 operated patients. The Annals of thoracic surgery 76.3 (2003): 886-891.

5. Rodriguez PM, Freixinet JL, Hussein M, Valencia JM, Gil RM, Herrero J, Hidalgo AC (2008) Side effects, complications and outcome of thoracoscopic sympathectomy for palmar and axillary hyperhidrosis in 406 patients. Eur J Cardiothorac Surg 34:3 514-19

6. Oncel M, Sunam GS, Esref E, et al. Bilateral thoracoscopic sympathectomy for primary hyperhidrosis: a review of $\mathbf{3 3 5}$ cases. Cardiovascular Journal of Africa 2013;24:137-40.

7. Hornberger J, Grimes $\mathrm{K}$, Naumann $\mathrm{M}$, et al. Recognition, diagnosis and treatment of primary focal hyperhidrosis. J Am Acad Dermatol 2004;51:27486.

8. Ro KM, Cantor RM, Lange KL, Ahn SS. Palmar hyperhidrosis: evidence of genetic transmision. $J$ Vasc Surg 2002;35:382-6.

9. Campos JRM, Kauffman P, Werebe EC, Filho LOA, Kusniek S, Wolosker N, Jatene FB (2003) Quality of life, before and after thoracic sympathectomy: report on 378 operated patients. Ann Thorac Surg 76:886-91

10. Moreno-Lorenzo C, Castro-Sanches AM, GuisadoBarrilao R, Linares-Solano J, Ruiz-Villaverde R, Villaverde-Gutierrez C. Dermatologic iontophoresis in palmar hyperhidrosis: immunohistochemical study. Eur J Dermatol 2010;20:235-6.

11. Grunfeld A, Murray CA, Solish N. Botulinum toxin for hyperhidrosis: a review. Am J Clin Dermatol 2009;10:87-102.

12. Gregoriou S, Rigopoulos D, Makris M, Liakou A, Agiosofitou E, Stefaneki C, et al. Effects of botulinum toxin A therapy for palmar hyperhidrosis in plantar sweat production. Dermatol Surg 2010;36:496-8. 
13. Karimian-Teherani D, Panhofer P, Ringhofer C, Jakesz R, Prager M, Zacherl J, et al. New epidemiological aspects of patients with severe hyperhidrosis presenting for sympathetic surgery. J Eur Acad Dermatol Venerol 2009;23:651-5.

14. Assalia A, Bahouth $H$, Ilivitzki A, Assi Z, Hashmonai M, Krausz MM. Thoracoscopic sympathectomy for primary palmar hyperhidrosis: resection versus transection: a prospective trial. World J Surg 2007;31:1976-9.

15. Campos JRM, Kauffman P, Werebe EC, Filho LOA, Kusniek S, Wolosker N, Jatene FB (2003) Quality of life, before and after thoracic sympathectomy: report on 378 operated patients. Ann Thorac Surg 76:886-91

16. Juan JF, Laureano M, Jose MM, Gonzalo V (2009) Effectiveness of sympathetic block by clipping in the treatment of hyperhidrosis and facial blushing. Interact Cardiovasc Thorac Surg 9:970-2

17. Leão LEV, Oliveira R, Szulc R, Mari JJ, Crotti PLR, Gonçalves JJS (2003) Role of video-assisted thoracoscopic sympathectomy in the treatment of primary hyperhidrosis. Sao Paulo Med J 121 (5):191-7

18. Rajesh YS, Pratap CP, Woodyer AB (2002) Thoracoscopic sympathectomy for palmar hyperhidrosis and Raynaud's phenomenon of the upper limb and excessive facial blushing: a five year experience. Postgrad Med J 78:682-4

19. Nawrocki, S.; Cha, J. The etiology, diagnosis and management of hyperhidrosis: A comprehensive review. Part I. Etiology and clinical work-up. J. Am. Acad. Dermatol. 2019, 81, 657-666.

20. Strutton RD, Kowalsky JW, Glaser DA, Stang PE. US prevalence of hyperhidrosis and impact on individuals with axillary hyperhidrosis: results from national survey. J Am Acad Dermatol 2004;51:241-8. 21.

21. Lear W, Kessler E, Solish N. An epidemiological study of hyperhidrosis. Dermatol Surg 2007;33:69-75.

22. Karimian-Teherani D, Panhofer P, Ringhofer C, Jakesz R, Prager M, Zacherl J, et al. New epidemiological aspects of patients with severe hyperhidrosis presenting for sympathetic surgery. J Eur Acad Dermatol Venerol 2009;23:651-5.
23. Hamm H, Naumann MK, Kowalsky JW, Kutt S, Kozma C, Teale C. Primary focal hyperhidrosis: disease characteristics and functional impairment. Dermatology 2006;212:343-53.

24. Stolman LP. Treatment of hyperhidrosis. Dermatol Clin 1998; 16: 863-867.

25. Shelly WB, Talanin NY, Shelly ED. Botulinum toxin therapy for palmar hyperhidrosis. J Am Acad Dermatol 1998; 38: 227-229

26. Munia MAS, Wolosker N, Kauffman P, Campos JR, Leão PP (2008) Sustained benefit lasting one year from T4 instead of T3-T4 sympathectomy for isolated axillary hyperhidrosis. Clinics (Sao Paulo) 63(6):771-74

27. Munia MAS, Wolosker N, Kauffman P, Campos JR, Leão PP (2007) A randomized trial of T3-T4 versus T4 sympathectomy for isolated axillary hyperhidrosis. $J$ Vasc Surg 45:130-33

28. Chen YB, Ye W, Yang WT, Shi L, Guo XF, Xu ZH, Qian YY (2009) Uniportal versus biportal videoassisted thoracoscopic sympathectomy for palmar hyperhidrosis. Chin Med J (Engl) 122 (13):1525-28

29. Krasna MJ (2008) Thoracoscopic sympathectomy: a standardized approach to therapy for hyperhidrosis. Ann Thorac Surg 85:764-67

30. Garcia F, Espania A. Usefulness of bilateral sympathectomy using video-assisted thorascopic surgery in the treatment of essential hyperhidrosis. Actas Dermosifiliogr 2008; 99: 523-711.

31. Lardinois D, Ris HB. Minimally invasive videoendoscopic sympathectomy by use of a transaxillary single port approach. Eur J Cardiothorac Surg 2002; 21: $67-70$.

32. Cohen Z, Levi I, Pinsk I, Mares AJ. Thoracoscopic upper thoracic sympathectomy for primary palmar hyperhidrosis-the combined paediatric, adolescents and adult experience. Eur J Surg 1998; 580(Suppl): 5-8. 


\begin{tabular}{|c|l|l|l|}
\hline \multicolumn{3}{|c|}{ AUTHORSHIP AND CONTRIBUTION DECLARATION } \\
\hline Sr. \# & \multicolumn{1}{|c|}{ Author(s) Full Name } & \multicolumn{1}{|c|}{ Contribution to the paper } & Author(s) Signature \\
\hline 1 & Javed Mirdad Tarar & First Author \\
\hline 2 & Kashif Nadeem & Second Author \\
3 & Durre Sadaf Khan & Third Author
\end{tabular}

